Open Access

\title{
Leisure participation patterns and gender wage gap-evidence from Chinese manufacturing industry
}

\author{
Xiang $\mathrm{Wei}^{\mathrm{i}^{*}}$, Emily $\mathrm{Ma}^{2}$ and Pengfei Wang ${ }^{3}$
}

\author{
* Correspondence: \\ weixiang@cass.org.cn \\ ${ }^{1}$ National Academy of Economic \\ Strategy, Chinese Academy of Social \\ Sciences, 9th floor of Zhong Ye \\ Building, 28\# West of ShuGuang \\ Road, Chaoyang District, Beijing, \\ China \\ Full list of author information is \\ available at the end of the article
}

\begin{abstract}
Background: This paper aims at explaining the gender wage gap in the labor market from the perspective of leisure participation patterns between men and women. The traditional view is that time and effort spent in childbearing activities are the major sources of gender wage gap. Women, particularly in Chinese society, are the major career of children and share a large portion of housework, thus lacking time for the accumulation of human capital. This directly affects women's employment status in the labor market as well as wage gaps with men.

Methods: This study empirically examines the within-job wage differences between men and women in the same occupation and establishment in relationship to their leisure participation patterns. Data were collected via time diary survey from "blue-collar" employees of a Chinese factory, producing parts for cars.

Results: The results showed that differences of time allocation in social time and passive leisure time between men and women contribute to gender wage gap. The study also uncovered the hidden gender discrimination in a male-dominated society.

Conclusion: This study calls for institutional arrangements by the Chinese government to acknowledge women's need and rights in workplace.
\end{abstract}

Keywords: Gender, Wage gap, Leisure participation pattern, China

\section{Background}

The gender wage gap has been a popular topic which has attracted researchers' attention for decades (e.g., Bellas et al. 2001). In the labor market, a common phenomenon being observed is that male employees' wages are higher than females' (Kara 2006). However, researchers have identified a number of factors that contribute to wage gaps between men and women (e.g., Becker 1985; Baxter 1992; Blau and Kahn 1994; Jacobsen and Levin 1995; Gustafsson and Li 2000; Chi and Li 2014). An important cause general agreed is that women's work/career is often interrupted because of bearing children. When women and men are equally involved in the work at the same time, women spend more effort in taking care of their families, which may reduce the amount of effort they spend in jobs, thus affecting women's income (Becker 1985; 1991). In the USA, Japan, the UK, Turkey, and Russia, wage differences between men and women have gradually reduced for the past few decades (Jane 1998; Heather 2000; Kara 2006; Glinskaya and Mroz 2000). In the USA, the Bill of Rights and the Labor Law play important roles in

(c) The Author(s). 2017 Open Access This article is distributed under the terms of the Creative Commons Attribution 4.0 International License (http://creativecommons.org/licenses/by/4.0/), which permits unrestricted use, distribution, and reproduction in any medium, provided you give appropriate credit to the original author(s) and the source, provide a link to the Creative Commons license, and indicate if changes were made. 
reducing the gender discrimination and offering equal right of education and trainings (Altonji and Blank 1999).

However, situation and trends on wage gaps seems to be different from what have been experienced in developed countries. Chi and Li (2014) compared the wage difference between men and women in Chinese labor market since the 1980s and found that wage gaps are gradually increasing while differences in productivity was not the cause for the difference. In China, the average level of education attained by women is higher than that by men. For example, in 2013, female students accounted for $51.74 \%$ in all colleges and universities in China (China Education Development Report 2014). Influenced by the Chinese traditional culture and "One family one child" policy, grandparents are often involved in raising grand-children (Kaige et al. 2013). This gives women opportunities to continue to work after having children. Here, it seems that traditional human capital theories are unable to explain the gender wage gap in China when women have equal levels of education, productivity, and working time. We, therefore, propose that the difference in the allocation of time between men and women might be an important cause of wage differences. We justify our proposition from the following two aspects. Firstly, social capital (social capital is a collection of actual or potential resources in the process of social interaction in the form of relational network (Villalonga-Olives and Kawachi 2015), and it emphasizes specific benefits that flow from the trust, reciprocity, information, and cooperation associated with social networks) has a significant effect on income as supported by many researchers (Min 2008; Zhao 2012). Secondly, compared with females, male employees prefer allocating more time for social activities (Tan and Li 2002; Min 2008), which helps the accumulation of social capital. The logical is as follows: the gender's difference in the allocation of time decides that the men have more leisure time spending on social activities, and the social activities make males have more chances to accumulate social capital, which lead the men have income advantage in labor market.

This study examines gender differences in salaries for male and female employees in the same occupation. We assessed whether men's and women's salary differences were caused by different life patterns. The study fills theoretical gap by providing evidence of gender-based wage differences from the perspective of life patterns and by showing how wages differ based on leisure participation patterns in China.

\section{Literature review}

\section{Human capital theory}

The human capital theory is the theoretical basis to explain wage gap in the labor market (Becker 1964; Mincer 1974). Human capital (e.g., education, training experience, and health condition) is an important indicator of the value of employees, and it also links to the economic value employees may create for organizations (Goldin and Katz 2007; Daron and Autor 2012; Miriam et al. 2010). Although gender is one of the variables that have been included when analyzing personal incomes (Mincer 1958), it is hard to use this theory to exactly explain wage gaps between men and women. In fact, the gender wage gaps still exist in spite of the women have the same education level and production with the men (Phelps 1972), and we need more theories to explain the phenomena. 


\section{Gender wage gap}

Economists have shown great interest in the study of wage gap between men and women (Loureiro et al. 2004). Michael (1973) found that although female employees with the same level of education worked harder than male employees, they often get less wage. Altonji and Blank (1999) analyzed the hourly wage rates of male and females employees in the USA using the data from the Bureau of Labor Statistics and found that male employees' average hourly wage was US \$18.96 while female employees' average hourly wage was only US $\$ 12.25$. Empirical analyses have generated controversial evidence in China. For instance, Maurer-Fazio et al. (1999) and Gustafsson and Li (2000) found that female's wages have deteriorated relative to males' wages and that wage difference has increased in cities during the economy transition period. In contrast, Liu et al. (2000) reported that wage discrimination against women was less prevalent in organizations that are more market-oriented. Dong and Zhang (2009) also suggested that the relative wage of female workers related to productivity was higher than that of male workers in state-owned enterprises (SOEs), suggesting that unskilled female workers in SOEs receive wage subsidies in China.

Despite the popularity of wage gap in literature, there are inconsistencies in sources of wage gap (Kara 2006). Researchers generally agree that level of education, experience, ability, labor market, and position levels jointly affect the productivity of employees, which in turn affects wages. However, even if team members have the same skills, level of education, training experience, working experience, and the level of productivity, wage gap between men and women still exists (Phelps 1972). In the Chinese labor market, it is generally agreed admitted that enterprises seem to show preference for male employees (Bishop et al. 2005). One explanation is that male employees are more efficient than female employees (Blau and Kahn 1992). Through research on wage changes, according to the existing literature, under the same circumstance, why gender wage differences still exist? The paper attempts to answer this question from the perspective or time allocation, particularly leisure time allocation.

\section{Gender difference in time allocation}

Based on large number of data, Mincer (1982) found that time allocation has a greater substitution effect ${ }^{1}$ than income effect ${ }^{2}$ on women than on men. It gives us a new perspective on the wage difference between men and women, namely other sources of gender wage differences in terms of the time allocation. According to the gender role theory, husbands take the instrumental function, so they focus on professional and external social activities to maintain the relationship between the family and the outside world; on the other hand, wives take the ideographic function, so they focus on the family's internal affairs in order to maintain the relations inside the family. The division of labor within families determines the roles of husbands and wives. The husband's role is fixed in the external affairs of the family, while the wife has both mother and family management roles (Bales and Parsons 1956; Becker 1965). Therefore, women are main undertakers of housework, leading women to devote less effort to the job market, thus affecting their income levels.

According to traditional gender roles and time allocation, men tend to have more free time and leisure time than women (Thrane 2000; Mattingly and Bianchi 2003; Sayer 2005; Beck and Arnold 2009). Marriage and children exacerbate the income gap 
between men and women (Mattingly and Bianchi 2003). However, in recent years, research shows that the traditional time allocation modes of men and women are constantly changing. More women are engaged in the labor market, and men and women tend to share a more equal with housework load (Tanja 2015). According to the time-use data of residents of seven developed countries, Gimenez-Nadal and Sevilla (2012) found that men are reducing time spent in work and increasing time spent in housework, while women are just the opposite. Bara and Leukhina (2011) also confirmed the above findings based on data of dual-employee families from 1959 to 1999. US census data also shows that the percentage of female employees have risen from 33 to 76\% from 1960 to 2000. According to the World Bank (2012), women account for $40 \%$ in the global labor market, $43 \%$ for the agricultural sector, and more than half of students. However, a significant increase in labor participation has not led to a significant increase in women's wages (Jaggar 2013). Men still enjoy more leisure time and higher wage levels (Beblo and Robledo 2008).

With increasing females join the labor market and males participate in housework more equally with men, traditional theories, such as the gender role theory, the labor division theory within the family, and the income replacement utility theory, seem unable to effectively explain wage gaps between men and women. Therefore, research attention is needed on causes for wage gaps between men and women from new perspectives.

\section{Social capital and time allocation}

Social capital is a collection of actual or potential resources in the process of social interaction in the form of relational network (Villalonga-Olives and Kawachi 2015). Resources include not only funds but also rights, knowledge, information, time and opportunities, and other intangible material resources (Tan and Li 2002). Social capital is produced through interactions between people and between individuals and organizations. The World Bank has made important contributions to the measurement of social capital and treats it as a multidimension construct with social networks and informal relations being important measure dimensions (Zhao 2012). Social capital is often referred to as "Guanxi" in Chinese contexts, and it plays an extremely important role in the Chinese society (Bian and Zhang 2013). Males and females also invest in social capital in different ways (Richard and Lundberg 1981). For example, Leeves and Herbert (2014) found that females invest more in nonmarket social capital while males engage more in political and economic associations and professional bodies which may help produce important knowledge and networks contributing to their career advancement. Duin et al. (2015) found that in Chinese culture, women are main caregivers in families and they have less time and energy to engage in physical activity and/or hobbies, which are important processes of accumulating social capital. On the other hand, men in Chinese society participate a lot more in entertainment, social gatherings, and leisure activities than women (Zhao 2012). Kim (2014) also found that women are less likely to utilize social capitals for their work and also are less likely to start up business compared to men. Therefore, the Chinese males are in a better position to produce social capital and, therefore, can take advantage of social capital and produce more economic outcomes (Zhang 2008).

In summary, we know that the wage gap between men and women exists for a long time. Although the human capital theory (Lucas 1986) and the household economics (Becker 1965) 
have made a great contribution to explaining the difference of wages, it is difficult for us to explain the reason why gender wage differences still exist, faced with the gradually increasing women's participation in the labor market, education level, and other human capital determinants. This paper wants to explore the reason for wage differences between men and women covered by the gender discrimination from the perspective of gender differences in leisure time allocation which has a big effect on social capital.

\section{Methods}

\section{Subject of the study}

The study was conducted at a manufacturing company in Xiangyang City, Hubei Province in China. Production line staffs were selected as subjects for the study. The company produces parts for cars, and it is a publicly listed company. Seventy-four employees working in the same assembly line participated in the study. These employees work 7 days per week without ordinary holidays. Most of them are migrant workers from another province in China. The selected participants of the study ensured the consistency between position, working environment, and the background of the experimental objects, which helps improve the credibility of the research conclusions.

\section{Data collection process}

A field observation was performed in July and August 2014. Twenty students were recruited and trained to observe employees' job performance using the log sheet. Two teachers were responsible for coordinating the work onsite. Two training sessions were provided to students. Each student was responsible for real-time tracking of four workers' work behaviors during working hours. They recorded the content of every worker's time use every $10 \mathrm{~min}$ and formed a closed loop time log per day. We recorded the allocation of workers' leisure time the following morning based on students' logbooks. Anonymous investigation, double-blind entering, and repeated retrials were used to ensure the reliability of data collection. Two teachers checked all students' time log tables on a daily basis. Immediate corrections were made if any mistakes and omissions were found.

A total of 74 participants remained after elimination of false reporting and workers taking leave, with 666 valid observation points collected in 9 days. Data were analyzed using SPSS, and specific data analysis method was also used for this study, including regressions. Table 2 summarizes the demographic profile of participants in this study.

\section{Variable selection}

The variables of the study can be divided into three categories. The first category includes demographic variables, such as gender, age, education, and marital status. The second category includes job performance variables, such as working hours and monthly wages. The last category includes time allocation variables. According to Aguiar and Hurst (2007), workers' time can be divided into market time, nonmarket production time (i.e., housework time), child care time, and leisure time. Following this approach, time allocation variables included in this study contain the following: (1) sleeping time L1 and (2) leisure time LT (including sports time L2, literary time L3, recreation time L4, social time L5, enjoy time L6, passive leisure time L7, housework time 
L8, and gross leisure time at work PLT). Working hours (WL) in this study equals $24 \mathrm{~h}$ minus leisure time (LT) and sleep time (L1). Specific descriptions on each type of time allocation variables are included in Table 1.

\section{Results and discussion}

\section{Basic information analysis}

\section{Basic information of samples}

The majority of the sample are female with a total of 47 female employees, accounting for $63.5 \%$ of the total participants. There are 27 male employees, accounting for $36.5 \%$ of total employees. Employees' level of education is relatively low, and all are high school or technical school graduate and below. Among them, the proportion of junior high school and the below is 39.2\%; high school and technical secondary school graduate is in the majority, accounting for $60.8 \%$.In terms of age, workers below 35 years old accounted for $58.25 \%$ and 35 years old and above accounted for $41.8 \%$. Considering working experiences, $45.9 \%$ of employees have more than 5 years of working experience. In terms of family structure, the respondents were mostly married (78.4\%), while only $28.4 \%$ of married couples have children. The demographic information of the sample is shown in Table 2.

\section{Correlation test}

The result of the correlation test between variables shows the significant relationship between gender, standard hours, working age, and income of employees. The aim of the paper is to trace the reason for gender wage gap. From Table 3, we can find out that gender, standard hours, and working age are the main sources of income gap. In the study of gender wage gap, we should control the differences caused by standard hours and working age, so that we can assess if the real differences are caused by gender discrimination.

Table 1 Variable name and explanation

\begin{tabular}{|c|c|}
\hline Variable name & Explanation \\
\hline Standard hours & $\begin{array}{l}\text { The specified number of artifacts workers must finish in the time given } \\
\text { based on the average performance of the team. }\end{array}$ \\
\hline Income & $\begin{array}{l}\text { Income this month includes performance-related pay, seniority pay, } \\
\text { and comprehensive evaluation wages. }\end{array}$ \\
\hline Sleeping time L1 & The time for sleeping, washing, and marital activities after work \\
\hline Sports time $\mathrm{L} 2$ & The time for walking, taking exercise, keeping fit, and making beauty after work \\
\hline Literary time $\mathrm{L} 3$ & $\begin{array}{l}\text { The time for listening to music, reading, drawing, and reading newspapers } \\
\text { and magazines after work }\end{array}$ \\
\hline Recreation time $L 4$ & $\begin{array}{l}\text { The time for watching } T V \text {, playing microblog and games, playing computers, } \\
\text { chatting online, surfing the Internet, watching plays and films, and other } \\
\text { recreational activities after work }\end{array}$ \\
\hline Social time L5 & The time for dining out, talking business and singing after work \\
\hline Enjoy time L6 & $\begin{array}{l}\text { Different from the entertainment time, the enjoying time means the time for going } \\
\text { together, shopping, having a foot massage, and other enjoying consumption } \\
\text { activities after work. }\end{array}$ \\
\hline Passive leisure time $L 7$ & $\begin{array}{l}\text { The time for playing mahjong, smoking, drinking, and other negative leisure } \\
\text { activities after work }\end{array}$ \\
\hline Housework time L8 & $\begin{array}{l}\text { The time for cleaning rooms, cooking, taking care of children and family members, } \\
\text { and buying groceries after work }\end{array}$ \\
\hline Gross leisure time PLT & The gross leisure time at work \\
\hline
\end{tabular}


Table 2 Sample characteristics

\begin{tabular}{llllllll}
\hline Demographics & Items & Number & Percent & Demographics & Items & Number & Percent \\
\hline Gender & Male & 27 & $36.5 \%$ & Marital status & Unmarried & 16 & $21.6 \%$ \\
& Female & 47 & 63.5 & & Married & 58 & $78.4 \%$ \\
Education level & Primary school & 29 & $39.2 \%$ & Age & $<35$ years old & 42 & $58.2 \%$ \\
& High school & 45 & $60.8 \%$ & & $\geq 35$ years old & 31 & $41.8 \%$ \\
& and above & & & & & & \\
\multirow{5}{*}{ Babies } & Yes & 21 & $28.4 \%$ & Work experience & $\leq 5$ years & 40 & $54.1 \%$ \\
& No & 53 & $71.6 \%$ & & $>5$ years & 34 & $45.9 \%$ \\
\hline
\end{tabular}

\section{Analysis of the source of gender wage gap}

Analysis of the source of gender wage gap

From the above analysis, we know that, before studying the sources of gender wage discrimination, the difference analysis between income levels, working age, and standard hours of employees of different gender is very necessary. The data of Table 4 shows that there are significant income differences between men and women. Every month, male employees' income is 678.42 yuan $^{3}$ more than females. Compared with women, men have a longer working age, which is in average 0.448 year longer than women. Moreover, men also have longer standard hours, ${ }^{4}$ which is $0.4 \mathrm{~h}$ more than women per day.

Table 4 shows that the total gender wage gap is 678.24 yuan/month with the influence of working age and standard hours included. However, the true level of wage discrimination between men and women, if any, should be lower than 678.24 yuan/ month. The computational method of wage gap caused by working age is working age gap between men and women multiply by per capita working age wage, namely

Total gender wage gap $=$ Mean difference of income by gender

Working age wage gap = Average income per one year * Mean difference of working age

Standard hours wage gap = Average income per one hour * Mean difference of

Standard hour

By calculation, the wage gap caused by working age is 202.02 yuan. The computational method of wage gap caused by standard hours is standard hour gap between men and women multiply by per capita wage per hour. By calculation, the wage gap caused by standard hours is 113.85 yuan. The specific values can be seen in Table 5 .

After eliminating wage differences caused by standard hours and working age, the true gap caused by gender difference should be

Table 3 The result of correlation test

\begin{tabular}{lllll}
\hline Variables & & Gender & Standard hours & Work age \\
\hline Income & Pearson value & $.442^{* *}$ & $.411^{* *}$ & $.592^{* *}$ \\
& Asymp.Sig (2-tailed) & .000 & .000 & .000 \\
& $N$ & 74 & 74 & 74 \\
\hline
\end{tabular}

Fourteen variables including level of education, marital status, and leisure time show no significant relationship with income level, so we omit them in the table

*Two-tailed significance at the 0.10 level; ${ }^{* *}$ Two-tailed significance at the 0.05 level 
Table 4 The one-way ANOVA of variables on gender

\begin{tabular}{llllll}
\hline Variable & Male & Female & Mean difference & $F$ & Sig. \\
\hline Income & 3096.76 & 2418.34 & 678.42 & 20.090 & .000 \\
Work age & 6.196 & 5.748 & 0.448 & 1.505 & 0.224 \\
Standard hours & 9.62 & 9.22 & 0.4 & 0.10 & 0.921 \\
\hline
\end{tabular}

Gender wage discrimination $=$ total gender wage gap

$$
\begin{aligned}
& \text { - working age wage gap } \\
& \text { - standard hours wage gap }
\end{aligned}
$$

Using the data from Tables 4 and 5, this equals to

$$
\text { Gender wage discrimination }=678.42-202.02-113.85=362.55 \text { yuan }
$$

Therefore, the true difference of wages caused by gender is 362.55 , which is about $15 \%$ of a female worker's monthly wage.

\section{Stability test for results}

According to the human capital theory, demographics variables such as level of education, age, marital status, and number of children may have impacts on wages. In order to assess if these variables influence wages, we performed a number of contingency analyses. Details are summarized in Table 6. Table 6 shows that no statistical significant differences were observed between level of education, age, marital status children, and men's and women's wages. In another word, the main sources of gender wage gaps are working experiences, working hours, and gender discrimination.

\section{Analysis of the time allocation gap}

Bales and Parsons (1956) gender theory suggested that men and women have different roles in society, whereas men should be "outside the home" while women should be "inside the home." Mincer (1984) further pointed in the comparative advantage theory that women's substitution effect is greater than income effect, which is the theoretical explanation as to why females earn lower wages than males. Becker (1985) also found that due to responsibilities such as childbearing and taking care of the household, women pay relatively less efforts on work, thus affecting their incomes. However, recent research findings show that women are paying increasing more time and energy at workplaces, while men tend to spend more time on housework (e.g., Gimenez-Nadal and Sevilla 2012; Tanja 2015). Especially in China, due to the influence of Chinese traditional culture and living habits, the work of raising children and doing housework are often done by grandparents, giving married women more time and freedom to do their job.

The detailed records and researches for the time distribution of male and female employees each working day provide a reliable guarantee for verifying the above questions. The results of Table 7 show that male and female employees are almost identical in total amount of

Table $\mathbf{5}$ The earning gap from gender unit: yuan

\begin{tabular}{lllll}
\hline & Mean difference & Mean/income & Mean difference/income & Earning net gap by gender \\
\hline Work age & 0.448 & $450.94 /$ year & 202.02 & $678.42-202.02-113.85=362.55$ \\
Standard hour & 0.4 & $284.63 / \mathrm{h}$ & 113.85 & \\
\hline
\end{tabular}


Table 6 Crosstab analysis of income on different groups

\begin{tabular}{lllll}
\hline Items & Primary school & High school & $F$ & Sig. \\
\hline Male & 3010.23 & 3140.02 & 1.773 & 0.195 \\
Female & 2410.74 & 2423.97 & .011 & 0.916 \\
& Unmarried & Married & $F$ & Sig. \\
Male & 2769.96 & 3260.16 & .280 & 0.601 \\
Female & 2242.94 & 2449.04 & .707 & 0.405 \\
& No babies & Have babies & $F$ & Sig. \\
Male & 3004.96 & 3159.87 & .430 & 0.518 \\
Female & 2399.20 & 2423.51 & .179 & 0.675 \\
& $<35$ years old & $\geq 35$ years old & $F$ & Sig. \\
Male & 3229.25 & 2633.03 & 1.508 & 0.231 \\
Female & 2241.46 & 2573.99 & 1.470 & 0.232 \\
\hline
\end{tabular}

leisure time, sleeping time, and working time. No significant differences were observed between males and females in their allocation of different types of leisure time.

The in-depth analysis of the leisure time allocation of male and female employees can depict the difference in lifestyles. From Table 8, male and female employees are generally consistent with the allocation of sports time, recreation time, enjoy time, housework time, and leisure time at work, and no significant difference was observed. However, significant differences on social time and passive leisure time allocation between male and female employees were observed $(p<0.05)$. Compared with female employees, male employees were much more active in social time and passive leisure time than women. Detailed information is summarized in Table 8. This finding indicated that the biggest lifestyle difference between male and female employees lies in social activities and passive leisure activities (such as partying and drinking and playing mahjong).

\section{Quantitative analysis of gender wage gap}

To better show the relationship between gender wage gap and other variables, further analyses were performed. Using wages as the dependent variable $(Y)$ and gender, working experience of years, and work efficiency, respectively, $X_{1}, X_{2}$, and $X_{3}$, social time L5 and passive leisure time L7 are two independent variables; ordinary least square regression analysis was performed. The theoretical model is based on above rules:

$$
Y=\beta_{0}+\beta_{1} X_{1}+\beta_{2} X_{2}+\beta_{3} X_{3}+\beta_{4} L_{5}+\beta_{5} L_{7}+u
$$

According to the prior theories and thoughts, the wage level increases with the increase of work efficiency and working age, so $\beta_{2}>0$ and $\beta_{3}>0$. Social time can increase social capital and can cause the rise of wages, so $\beta_{4}>0$ and $\beta_{5}>0$. Men's wages are

Table 7 The $T$ test of time pattern on gender

\begin{tabular}{lllll}
\hline Items & Male & Female & $F$ & Sig. \\
\hline Leisure time & 366.9173 & 365.5457 & .489 & .487 \\
Sleeping time & 561.6123 & 528.7489 & .203 & .653 \\
Working time $^{\mathrm{a}}$ & 511.4701 & 545.7054 & 3.556 & .063 \\
\hline
\end{tabular}

${ }^{a}$ Working hours equals $24 \mathrm{~h}$ minus leisure time and sleep time 
Table 8 The $T$ test of leisure time pattern on gender

\begin{tabular}{lllll}
\hline Items & Male & Female & F & Sig. \\
\hline Sports time & 10.5058 & 18.5340 & 3.14 & .081 \\
Recreation time & 147.7502 & 129.4085 & .325 & .570 \\
Social time & 31.5947 & 19.7210 & 5.23 & .02 \\
Passive leisure time & 15.0815 & 4.0319 & 14.50 & .000 \\
Enjoy time & 16.2626 & 22.1723 & .33 & .568 \\
Housework time & 51.2457 & 72.7511 & 2.772 & .100 \\
Leisure time in work & 91.9133 & 105.0532 & .911 & 0.343 \\
\hline
\end{tabular}

more than women's wages, so when the investigation object is a female, $X_{1}=1$, and wages reduce, so $\beta_{1}<0 . u$ is a random interference.

\section{Data preprocessing}

This paper uses observed data extending for 9 days. Data analysis using ordinary least square regressions needs to satisfy three assumptions. The first assumption is data consistency, including consistency of sample size, sampling time, and statistical standard. Our data collected apparently conforms to this assumption. The second assumption is heteroscedasticity. Lastly, we need to make sure that normal distribution is satisfied with the data. We performed a number of tests to make sure that the second and third assumptions were also met.

a. Normality test

According to model (1), we use ordinary least square (OLS) method to analyze the data. The specific values and parameters can be seen in Table 9. We first performed the $K-S$ nonparametric test and $Q-Q$ plot test for the random interference $u$, in order to check if data met normality distribution assumption.

From Table 9, the $p$ value for $K-S$ nonparametric test is 0.661 , which is bigger than 0.05 , suggesting $u$ obeys normal distribution, $u \sim(0,4.10)$. In the $Q-Q$ plot, points in Fig. 1 are approximately linear, so data obeys normal distribution.

b. The test of heteroscedasticity and elimination

The study also performed the test of coefficient of rank correlation by Spearman. After removing the absolute value of residual error, we calculate the rank of $X$ and residual error whose absolute value is removed to study the relationship between the ranks of the absolute value of residual error and other variables. Since the

Table 9 One sample Kolmogorov-Smirnov test

\begin{tabular}{lll}
\hline Items & & Unstandardized residual $u$ \\
\hline$N$ & Mean & 74 \\
Normal parameters & Std. deviation & .0000000 \\
Most extreme difference & Absolute & $4.10586070 \mathrm{E2}$ \\
& Positive & .088 \\
& Negative & .088 \\
Kolmogorov-Smirnov $Z$ & & -.052 \\
Asymp.Sig (2-tailed) & & .760 \\
\hline
\end{tabular}

${ }^{\mathrm{a}}$ Test distribution is normal

${ }^{\mathrm{b} C a l c u l a t e d}$ from date 


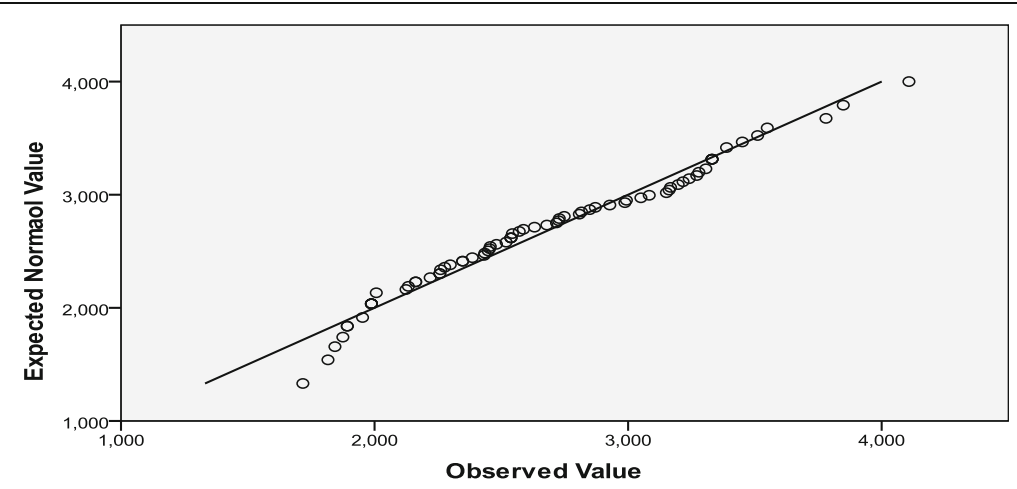

Fig. 1 Normal $Q-Q$ plot of unstandardized predicted value

value of significance is below 0.05 , the heteroscedasticity of the date exists.

We regard the variables whose $p$ value is below 0.05 as the weight and use the weighted least square (WLS) method to estimate and verify the models,

in order to eliminate heteroscedasticity.

\section{Revised model computation}

We use the method of weighted least square (WLS) to estimate and verify the models. The revised results can be seen in Table 10 .

Compared with model 1 (OLS), the degree of fitting and resolution of the regression equation, after removing heteroscedasticity, all increased in model 2 (WLS). The adjusted $R^{2}$ value is 0.694 , meaning that the resolution of the five variables towards dependent variable $y$ is $69.5 \%$, and its $f$ value and significance value is, respectively, 34.075 and 0.000 . $T$ test is to verify the significance of independent variable on the dependent variable. From Table 10, these five variables have passed the $T$ test. So the regression equation weighted by least squares estimation is as follows:

$$
Y=334.959-350.315 X_{1}+78.643 X_{2}+191.185 X_{3}+8.598 L_{5}+9.502 L_{7}
$$

The signs of coefficients of the parameters in Eq. (2) are fully consistent with our previous estimates, namely $\beta_{2}>0, s_{3}>0, \beta_{4}>0, s_{5}>0$, and $\beta_{1}<0$. The magnitude of coefficients

Table $\mathbf{1 0}$ The result of multivariable linear regression models

\begin{tabular}{|c|c|c|c|c|c|c|}
\hline \multirow[t]{2}{*}{ Items } & \multicolumn{2}{|c|}{ Model 1 (OLS) } & \multicolumn{2}{|c|}{ Model 2 (WLS) } & \multicolumn{2}{|c|}{ Model 3 (constraint) } \\
\hline & Coefficient & Sig. & Coefficient & Sig. & Coefficient & Sig. \\
\hline Constant & 296.088 & .658 & 334.959 & .585 & 1045.638 & .135 \\
\hline$x_{1}$ & -342.525 & .017 & -350.315 & .013 & -554.199 & .000 \\
\hline$x_{2}$ & 78.664 & .000 & 78.643 & .000 & 89.009 & .000 \\
\hline$x_{3}$ & 191.880 & .002 & 191.185 & .001 & 200.230 & .002 \\
\hline$L_{5}$ & 8.991 & .000 & 8.598 & .000 & a & \\
\hline$L_{7}$ & 9.630 & .034 & 9.502 & .034 & a & \\
\hline$R^{2}$ & .695 & & .715 & & .595 & \\
\hline Adj. $R^{2}$ & .673 & & .694 & & .577 & \\
\hline$F$ & 31.043 & & 34.075 & & 34.224 & \\
\hline Sig. & .000 & & .000 & & .000 & \\
\hline
\end{tabular}

an model 3, constraint condition: $\beta_{4}=o_{5}=0$, so the coefficient is zero, which is not shown in the equation 
indicates the influence and contribution of the independent variables to the dependent variables. The coefficient of $X_{1}$ is $-350.315,{ }^{5}$ which means that the employee's gender has negative effect on wages. That is, when the employee is female, the salary will decrease 350 yuan. It should be noted that Table 5 calculates the real gender wage gap as 362.55 yuan, which is almost equal with the coefficient of $X_{1}$ in the model. This further verifies the rationality of model 2, so job efficiency $\left(x_{2}\right)$, working age $\left(x_{3}\right)$, social time $\left(L_{5}\right)$, and passive leisure time $\left(L_{7}\right)$ have positive effects on wage level. The effect of work efficiency on wages is the most significant with the coefficient 191.185; working age follows as 78.643 ; the next is the passive leisure time and social time with their coefficients 9.502 and 8.598 , respectively.

\section{Robustness test}

The theoretical model constructed in this paper is to incorporate social time (L5) and passive leisure time (L7) into the employee wage decision model. In order to verify the robustness of model 2, a theoretical model is constructed as follows.

$$
Y=\beta_{0}+\beta_{1} X_{1}+\beta_{2} X_{2}+\beta_{3} X_{3}+\beta_{4} L_{5}+\beta_{5} L_{7}+u
$$

We assume the model with constraint conditions of no relationship between income and social time (L5) and passive leisure time (L7), namely

$$
H_{0}: \beta_{4}=\beta_{5}=0
$$

So the regression equation with constraint conditions is

$$
Y=\beta_{0}+\beta_{1} X_{1}+\beta_{2} X_{2}+\beta_{3} X_{3}+u
$$

We insert the data into Eq. (4) and get the results as model 3 in Table 10.

The data of Table 10 is under the condition of $R_{R 2}=0.577$, but without the condition of $R_{\mathrm{UR}}^{2}=0.694$

Now, examine the ratio $F$ in the condition of $H_{0}, o_{4}={ }_{5}=0$

$$
F=\frac{\left(R_{\mathrm{UR}}^{2}-R_{R}^{2}\right) / m}{\left(1-R_{\mathrm{UR}}^{2}\right) /(n-k)}
$$

$m=$ the number of linear constraint conditions; $m=2$.

$k=$ the number of parameters in regression equation without constraint condition; $k=6$.

$n=$ frequency of observation, namely the number of samples; $n=74$.

Insert data into the above equation, we can get

$$
F=\frac{\left(0.694^{2}-0.577^{2}\right) / 2}{\left(1-0.694^{2}\right) / 68}=13>F_{0.05}(2,68)=3.15
$$

$F$ obeys the $F$ distribution with the $\mathrm{df}(m, n-k)$, namely $F-F(2,68)$. On the level of $5 \%$, $F_{0.05}(2,68)=3.15$. But $F$ value $(F=13)$ is greater than the critical value 3.15 , so our study rejects the null hypothesis $\left(H_{0}: \beta_{4}=\beta_{5}=0\right)$. That means the false of the regression equation with constraint conditions. As a result, the result of the revised model 2 is robust, namely

$$
Y=334.959-350.315 X_{1}+78.643 X_{2}+191.185 X_{3}+8.598 L_{5}+9.502 L_{7}
$$


Previous literature suggests that the occupation division is the intermediate variable which links wage differences between men and women and gender discriminations. Li (2008) studies the gender occupation division in China labor market and finds out that gender discrimination is the main reason for the wage difference between men and women. The author also discovers more serious wage gap in the same occupation than occupational wage gap, respectively, 22.5 and $15.7 \%$, which suggests the existence of serious longitudinal gender wage gap in the labor market. The results of this study are also confirmed by a number of researchers (e.g., Wang 2005; Li and Ma 2006; Yao and Huang 2008), who found that gender wage gap within occupations account for the majority of gender wage gap. In summary, previous researches suggest the following: firstly, the occupational division can cause wage difference; secondly, the wage gap between men and women is a serious matter. In order to eliminate wage gap caused by occupational division, the study of gender wage gap of employees doing the same types of jobs in the same industry will help us to further reveal the source of wage gap and the effects of gender discrimination on the wage gap.

Our paper found that except for other reasons, such as productivity and working age, gender wage gap caused by gender discrimination is 352.5 yuan, ${ }^{6}$ accounting for $52 \%$ of the wage difference between male and female (678.42 yuan); $48 \%$ of the wage difference can be explained by the human capital theory and the characteristics of employees, and $52 \%$ of that still are the unexplained part, which economists usually regard as the function of discrimination. The findings confirm the existence of gender discrimination towards female employees, even if the men and women employees with the same work efficiency, working age, level of education, and other factors.

We also examine two leisure variables (social time and passive leisure time) in the model. The results indicate that they both have significant effects on the wages of employees. Specifically, compared with women, male employees show more explicit preference for social time and passive leisure time. Taking all findings together, this paper finds a new perspective on wage differences between men and women. The gender allocation of leisure time will influence employees' wages, and their wages increase significantly with the rise of their social time and passive leisure time. We can explain it through the social capital theory. The social capital theory suggest, similar to physical capital and human capital, social capital is generated from the communications among people, as well as between the individuals and the organizations (Tan and Li 2002). Male employees are more active in participating in social activities (such as dining, singing, and gathering) and passive leisure activities (such as playing cards and drinking). These processes will help accumulate social capital of male employees. Caused by the quantity difference of the social capital, male employees will become the economic winner compared to female employees. In China, men are encouraged and inspired to establish broad social ties. In contrast, women are on the opposite, which lead to women's access to less social capital compared with men (Zhu 2008). Because of the close relationship between social capital and social resources, even if women and men work in the same workplace, their differences in social capital will directly affect the social resources individuals can access. This can also fully reflect in the professional title, position, and promotion of female employees (Zhang 2008).

This study also found that male and female employees are actually similar to allocating time for household activities in general, which is consistent with the findings of Gimenez-Nadal and 
Sevilla (2012). In addition, due to the influence of Chinese traditional culture, parents of employees bear the responsibility of taking care of children, so the child-rearing costs and the opportunity cost of doing household both are grossly overestimated to women in China.

\section{Conclusions}

The findings of this study suggest, first of all, the influence factors of gender wage differences include job efficiency, working age, and gender discrimination. The contribution rate of gender discrimination for wage difference is about $52 \%$. The influence factors of employees' wage level are the following: job efficiency, working age, gender, social time, and passive leisure time.

Secondly, the degree of gender discrimination in China is exaggerated. Chi and $\mathrm{Li}$ (2014) found that wage differences between Chinese men and women are gradually increasing, but that does not mean gender discrimination is increasing. In the opposite, with perfectness and completeness of Chinese laws and regulations, and the reducing of child-rearing costs and the opportunity cost of taking care of family, wage gap caused by gender discrimination is exaggerated.

Third, study on gender difference in time allocation can open up the "Black Box" of gender wage discrimination. The social time and passive leisure time in daily life can help establish broad social relationships, which helps gradually accumulate social capital. Caused by the quantity difference of the social capital, male employees can make use of rich social capital to become the economic winner. Besides, the male-dominated society hides gender discrimination in time allocation patterns. Thus, the government needs to implement working systems that allow flexible working hours or work from home, in order to reduce or eliminate the market's gender discrimination.

\section{Endnotes}

${ }^{1}$ Substitution effect: while the price of a good rises, other things remain the same; its opportunity cost rises.

${ }^{2}$ Income effect: It is the change in an individual's or economy's income and how that change will impact the quantity demanded of a good or service.

${ }^{3}$ Yuan is a monetary unit of China, one dollar equals to 6.52 yuan.

${ }^{4}$ The number of work pieces one worker should finish in the given time.

${ }^{5}$ This data is similar to 362.55 in Table 5.

${ }^{6}$ The wage gap calculated by two methods is, respectively, 342.525 and 362.55 , so we take the mean value of them (352.5).

\section{Acknowledgements}

We greatly appreciate the comments and suggestions given by the editor. The opinions expressed in this paper are those of the authors. All errors remain our responsibility.

Authors' contributions

All authors read and approved the final manuscript.

Authors' information

Wei Xiang is an associate professor in the National Academy of Economic Strategy, Chinese Academy of Social Sciences. Emily Ma is an associate professor in the Department of Tourism, Leisure, Hotel and Sport Management at Griffith University. Wang Pengfei is a PHD candidate in the Graduate School of Chinese Academy of Social Sciences. 


\section{Author details}

${ }^{1}$ National Academy of Economic Strategy, Chinese Academy of Social Sciences, 9th floor of Zhong Ye Building, 28\# West of ShuGuang Road, Chaoyang District, Beijing, China. ²Department of Tourism, Leisure, Hotel and Sport Management, Griffith University, Nathan Campus, 170 Kessels Road, Nathan, Queensland 4111, Australia. ${ }^{3}$ Graduate School of Chinese Academy of Social Sciences, Beijing 102488, China.

Received: 6 September 2016 Accepted: 18 January 2017

Published online: 17 February 2017

\section{References}

Aguiar M, Hurst E (2007) Measuring trends in leisure: the allocation of time over five decades. Quarterly Journal of Economics,122(3), 969-1006

Altonji JG, Blank RM (1999) Race and gender in the labor market. Handbook Lab Econ 3:3144-3213

Bara M, Leukhina O (2011) On the time allocation of married couples since 1960. Journal of Macroeconomics 33:491-510 Baxter, Denise, 1992. Domestic labour and income inequality, Work, Employment, and Society,6:2, 229-49

Beblo M, Robledo JR (2008) The wage gap and the leisure gap for double-earner couples. J Popul Econ 21(2):281-304 Beck ME, Arnold JE (2009) Gendered time use at home: an ethnographic examination of leisure time in middle-class families. Leis Stud 28(2):121-142

Becker GS (1964) Human capital. University of Chicago Press, Chicago

Becker GS (1965) A theory of the allocation of time. Econ J 75(299):493-517.

Becker GS (1991) Fertility and economy. University of Chicago- Economics Research Center

Becker G (1985) Human capital, effort, and the sexual division of labor. J Labor Econ 3(1):S53-58

Bellas ML, Neal Ritchey P, Parmer P (2001) Gender differences in the salaries and salary growth rates of university faculty: an exploratory study. Sociological perspectives, 44(2). Summer 2001:163-187

Bian Y, Zhang L (2013) The relationship between guanxi culture and guanxi social capital. J Humanit 16(01):107-113

Bishop J, Luo F, Wang F (2005) Economic transition, gender bias, and the distribution of earnings in China. J Econ Transit 13:239-259

Blau FD, Kahn LM (1992) The gender earnings gap: learning from international comparisons. Am Econ Rev Pap Proc 82: 533-538

Blau F, Kahn L (1994) Rising wage inequality and the U.S. gender gap. Am Econ Rev Pap Proc 84:2,23-28

Chi W, Li B (2014) Trends in China's gender employment and pay gap: estimating gender pay gaps with employment selection. J Comp Econ 42:708-725

China Education Development Report, 2014. Beijing: China Social Science Press

Daron A, Autor D (2012) What does human capital do? A review of Goldin and Katz's the race between education and technology. J Econ Lit 50(2):4264-63

Dong $X-y$, Zhang $L$ (2009) Economic transition and gender differentials in wages and productivity: evidence from Chinese manufacturing enterprises. J Dev Econ 88:144-156

Duin DK, Golbeck AL, Keippel AE, Ciemins E, Hanson H, Neary T, Fink H (2015) Using gender-based analyses to understand physical inactivity among women in Yellowstone County, Montana. Eval Program Plann 51:45-52

Gimenez-Nadal J, Sevilla A (2012) Trends in time allocation: a cross-country analysis. Eur Econ Rev 56:1338-1359 Glinskaya E, Mroz TA (2000) The gender gap in wages in Russian from 1992 to 1995. J Popul Econ 13(2):353-386 Goldin C, Katz LF (2007) Long-run changes in the wage structure: narrowing, widening, polarizing. Brook Pap Econ Act 2:135-165

Gustafsson B, Li S (2000) Economic transformation and the gender earnings gap in urban China. J Popul Econ 13:305-329 Heather (2000). Review of gambling in western culture: the age ofchance. Sociological Research Online.

Jacobsen J, Levin L (1995) The effects of intermittent labor force attachment on female earnings. Mon Labor Rev 118:14-19 Jaggar AM (2013) We fight for roses too: time-use and global gender justice. J Global Ethics 9(2):115-129

Jane (1998) Focus groups: a method of needs assessment. Journalof Continuing Education in the Health Professions, 18(18), 150-154

Kaige Y, Gengfeng N, Fan C (2013) The effect of skip-generation raising on personal development[J]. Journal of Science of Social Psychology 148(7):3-6

Kara O (2006) Occupational gender wage discrimination in Turkey. J Econ Stud 33(2):130-143

Kim SM (2014) The impacts of gender differences in social capital on microenterprise business start-up. J Wom Soc Work 29(4):404-417

Leeves GD, Herbert R (2014) Gender differences in social capital investment: theory and evidence. Economic Modelling $37: 377-385$

Li X (2008) Occupational division, gender discrimination and wage gap [J]. Finance and economics 39(2):88-96

Li S, Ma X (2006) Empirical study on gender wage gap and occupation segmentation for urban workers in China[J]. Chin J Popul Sci 5(1):2-13

Liu P, Meng X, Zhang J (2000) Sectoral gender wage differentials and discrimination in the transitional Chinese economy. J Popul Econ 13:331-352

Loureiro PRA, Carneiro FG, Sachsida A (2004) Race and gender discrimination in the labor market: an urban and rural sector analysis for Brazil. J Econ Stud 31(2):129-143

Lucas RE (1988) "On the Mechanism of Economic Development"[J], Journal of Monetary Economics,22, pp. 3-42

Mattingly MJ, Bianchi SM (2003) Gender differences in the quantity and quality of free time. The US Experience Social Forces 81(3):999-1030

Maurer-Fazio M, Rawski TG, Zhang W (1999) Inequality in the rewards for holding up half the sky: gender wage gaps in China's urban labor market, 1998-1994. Chin J 41:55-88

Mincer J (1958) Investment in human capital and personal income distribution. J Polit Econ 66(4):281-302

Mincer J (1974) Schooling, experience, and earnings. Columbia University Press, New York 
Mincer J, Jovanovic B (1982) Labor mobility and wages.Nber Working Papers

Mincer J (1984) Inter-Country Comparisons of Labor Force Trendsand of Related Developments: An Overview. (Vol.3, pp.S1-S32). National Bureauof Economic Research, Inc

Miriam B, Dean K, Antoinette S (2010) What capital is missing in developing countries? Am Econ Rev Pap Proc 100(20): 629-633

Parsons T, Bales RF (1956). Family, socialization, and interaction process. Am. J. Sociol. 7(615):142-145

Phelps ES (1972) The statistical theory of racism and sexism. Am Econ Rev 62:659-661

Richard S, Lundberg SJ (1981) Private discrimination and social intervention in competitive labor markets. Working paper, no.19-8

Sayer LC (2005) Gender, time, and inequality: trends in women's and men's paid work, unpaid work, and free time. Soc Forces 84:285-303

Spence AM (1973) Job market signaling. Q J Econ 87(3):355-74

Tan L, Li J (2002) What marriage and employment mean to women? - an analysis based on gender and social capital [J]. Collection and Women's Studies 47(4):5-11

Thrane C (2000) Men, women, and leisure time: scandinavian evidence of gender inequality. Leis Sci 22:109-122

Tiping Z (2008) Gender difference in social capital_evidence from cities in China Mainland [J]. Journal of Ningxia University (Humanities \& Social Sciences Edition) 30(4):88-99

Tanja van der Lippe, 2015, Time use and gender, International Encyclopedia of the Social \& Behavioral Sciences (second edition), Pages 369-372

Villalonga-Olives E, Kawachi I (2015) The measurement of social capital. Gac Sanit 29(1):62-64

Wang M (2005) Gender wage gap in China's urban labor market [J]. J Financ Econ 12:35-44

World Bank (2012) World development report 2012: gender equality and development. Tsinghua University press.

Yao G, Huang L (2008) Occupational segregation and its effect on estimates of the gender wage gap evidence from 2002 UHS data [J]. Journalof Chong Qing University (Social Science Edition) 14(2):53-58

Zhang M (2008) Gender difference and social capital inequality [J]. Forward 9:139-142

Zhao X (2012) Review of social capital measurement [J]. China Popul Resour Environ 22(7):127-133

Submit your manuscript to a SpringerOpen ${ }^{\circ}$ journal and benefit from:

- Convenient online submission

Rigorous peer review

- Immediate publication on acceptance

- Open access: articles freely available online

- High visibility within the field

- Retaining the copyright to your article

Submit your next manuscript at $>$ springeropen.com 